\title{
Orodental Biopsies in Females: A 23 Year Study
}

\author{
Sharma BP' ${ }^{1}$, Baral R ${ }^{2}$ \\ ${ }^{1}$ Assistant Professor of Dentistry, Patan Academy of Health Sciences, ${ }^{2}$ Associate Professor of Pathology, Patan Academy \\ of Health Sciences
}

Received: September 23, 2015 ; Accepted: March 15,2016

\begin{abstract}
Aims: Tissue diagnosis is an essential step to come to a confirmed diagnosis in oral lesions where clinical examination alone can often be difficult and inaccurate. The aim of this study was to assess the use of histopathological services by the dental department and to correlate the clinicopathological diagnosis in females who visited Patan Hospital.
\end{abstract}

Methods: This is a histopathological database analysis of dental biopsies in 23 years from 1989 to 2012 in Patan Hospital. The variables studied were age, sex, clinical and histopathological diagnosis. SPSS version 16 was used as an analytical tool.

Results: Out of 396 dental biopsies 203 (51.3\%) were females and 193 (48.7\%) were males with mean age 34.34 years and standard deviation of 17.9 years. Malignant tumor was seen in six female cases, all of which was squamous cell carcinoma. The total number of neoplastic and non-neoplastic conditions was $44 \%$ and $56 \%$ respectively in both the sexes.

Conclusions: Most diagnoses were benign in nature and had an inflammatory etiology.

Keywords: Fibroma, Lichen planus, Radicular Cyst

\section{INTRODUCTION}

Biopsy procedure is an important tool to confirm diagnosis in most of the surgical procedures where clinical examination alone can often be difficult and inaccurate. This holds true for the early detection of precancerous lesions. There are a number of reasons for the limited use of diagnostic histopathology services by the General Dental Practitioners. The primary reasons maybe due to lack of perceived value of biopsy in diagnosis, inadequate skill to perform biopsy and fear of clinical diagnostic error.

The aim of this study was to assess the use of histopathological services by the dental department, to correlate the clinicopathological diagnosis and to find out the histopathological spectrum oral lesions detected at Patan Hospital in female patients. The rational of this study is to provide an opportunity for close vigilance to the dentists in future regarding oral lesions in women. The objective of this study is to know the histopathological pattern and to categorise the oral lesions in terms of tissue diagnosis in women.

\section{CORRESPONDENCE}

Dr Bishnu Prasad Sharma

Assistant Professor of Dentistry,

Patan Academy of Health Sciences

Email bishnupsharma@pahs.edu.np

Phone No : 9841336289

\section{METHODS}

A limited database was reviewed and analyzed for the 396 dental biopsies taken in 23-year period from 1989 to 2012 at Department of Dentistry of Patan Hospital. The variables entered in the database were date, age, sex, treating dentist, clinical diagnosis and histopathological diagnosis. The tissue processing in the Department of Pathology used to be grossing of the specimen, processing in tissue processor, embedding and cutting into sections of 4 microns. All the slides were then stained with Hematoxyllin and Eosin stain and were reviewed by Pathologists.

\section{RESULTS}

The analyzable data of dental biopsy were 390 . Out of these 390 cases 203 (51.3\%) were females and 193 $(48.7 \%)$ were males. Neoplastic and non-neoplastic conditions were $44 \%$ and $56 \%$ respectively. Benign and malignant tumors were found to be $38 \%$ and $6 \%$ respectively in both males and females. Only six malignant cases were seen in females all of which was squamous cell carcinoma. Mean age was 34.34 years, median of 30 years and standard deviation of 17.9 years. Database reveals that no biopsy was sent to the lab in the years 1997 to 2000. Maximum number of cases of biopsy was sent in the years 2004 and 2005. 


\section{DISCUSSION}

The present study demonstrated that the overall distribution of the lesions analyzed was similar to the studies done in the United Kingdom, ${ }^{1}$ the United States of America ${ }^{2,3}$ and Brazil. ${ }^{4}$ Most of the specimens from the female patients analyzed over the period of 23 years in this hospital were inflammatory lesions or benign cystic lesions.

Majority of the specimen analyzed fell into inflammatory lesions, corroborating data from various studies. ${ }^{2,3}$ The frequency of periampullary inflammatory lesions was similar to that reported by Jones and Franklin. ${ }^{1}$ This maybe because the patients visited the dental department only to treat the decayed teeth which is usually associated with periapical inflammation. Inflammatory hyperplasia was the major entity seen amongst the inflammatory group with a total of 35 cases, which is consistent with the data of other studies. ${ }^{1,3}$

Lichen planus was seen in seven percent of the total cases and $4.2 \%$ of females which is much higher than those seen in other countries like Japan with only $0.7 \%$ and Sweden $1.9 \% .^{5}$

Fibroma was the most frequent diagnosis in the benign tumor group, supporting previous findings reported in many literatures. ${ }^{2}$ Squamous papilloma was seen in six cases (a total of 25 cases in both sexes) similar to studies done by Jones and Franklin. ${ }^{1}$ However, in their studies they had found higher occurrence of squamous papilloma and lower proportion of fibroma.

Malignant tumors accounted for $6 \%$ of all specimens, which is in accordance with the reports of other studies. $^{2,3}$ No case of Leukoplakia was diagnosed in females.

In the current study a total of 62 cases $(16 \%)$ were cystic lesions, a total of 28 cases were seen in females. Out of these cysts, 11 cases (39.2\%) were radicular cyst, 14 cases $(50 \%)$ were dentigerous cyst and rest of the cases were epidermal cysts. In a study done by Manor et al, radicular cysts were seen in $48 \%$ cases. ${ }^{6}$ Most of the odontogenic cysts are benign in nature but some of it may exhibit aggressive and destructive behavior locally. ${ }^{7}$ Odontogenic cysts and tumors develop during or after the formation of teeth. ${ }^{8}$

Fibrous hyperplasia (in the form of fibroepithelial polyp) was seen in almost 25 cases in males but only nine cases in females which is similar to the findings of Williams et al, ${ }^{9}$ where fibroepithelial polyps were one of the common lesions submitted.

It has been demonstrated that some factors, such as age, gender, socioeconomic status, prosthesis use, smoking and alcohol consumption, maybe associated with oral lesions. ${ }^{10}$ Unfortunately, these data are frequently not provided by surgeons when histopathological examination is requested. The associations related to gender and age observed in the present study could be explained by the cumulative effects of smoking and alcohol consumption. Since the information regarding behavioral factors was not available in the files of the laboratory, we were unable to evaluate these factors in the present study.

\section{CONCLUSIONS}

In conclusion, most diagnoses were benign in nature and had an inflammatory etiology. Age and gender may be considered demographic characteristics to be used for the differential diagnosis of major oral lesions.

\section{REFERENCES}

1. Jones AV, Franklin CD. An analysis of oral and maxillofacial pathology found in adults over a 30-year period. J Oral Pathol Med. 2006;35: 392-401.

2. Weir JC, Davenport WD, Skinner RL. A diagnostic and epidemiologic survey of 15,783 oral lesions. J Am Dent Assoc. 1987;115: 439-41.

3. Rossi EP, Hirsch SA. A survey of 4,793 oral lesions with emphasis on neoplasia and premalignancy. J Am Dent Assoc. 1977;94: 883-6.

4. Mendez M, Carrard VC, Haas AN, Lauxen Ida S, Barbachan JJ, Rados PV et al. A 10-year study of specimens submitted to oral pathology laboratory analysis: lesion occurrence and demographic features. Braz Oral Res. 2012;26: 235-41.

5. Ismail SB, Kumar SK, Zain RB. Oral lichen planus and lichenoid reactions: etiopathogenesis, diagnosis, management and malignant transformation. J Oral Sci. 2007;49: 89-106.

6. Manor E, Kachko L, Puterman MB, Szabo G, Bodner L. Cystic lesions of the jaws - a clinicopathological study of 322 cases and review of literature. Int J Med Sci. 2012;9: 20-6.

7. Goaz PW, White SC. Oral radiology: principles and interpretation. 3rd ed. St. Louis, Mo: Mosby-Year Book; 1994. p. 398-676.

8. Scholl RJ, Kellett HM, Neumann DP, Lurie AG. Cysts and cystic lesions of the mandible: clinical and radiologichistopathologic review. Radiographics. 1999;19: 1107-24.

9. Williams HK, Hey AA, Browne RM. The use by general dental practitioners of an oral pathology diagnostic service over a 20-year period: the Birmingham experience. Br Dent J. 1997;182: 424-29.

10. Carrard VC, Haas AN, Rados PV, Filho MS, Opperman RV, Albandar JM et al. Prevalence and risk indicators of oral mucosal lesions in an urban population from South Brazil. Oral Dis. 2011;17: 171-9. 